\title{
Enhanced Thermal Stability of Eugenol by Cyclodextrin Inclusion Complex Encapsulated in Electrospun Polymeric Nanofibers
}

\author{
Fatma Kayaci, Yelda Ertas, and Tamer Uyar* \\ UNAM-Institute of Materials Science and Nanotechnology, Bilkent University, Ankara 06800, Turkey
}

\begin{abstract}
Polyvinyl alcohol (PVA) nanofibers encapsulating eugenol (EG)/cyclodextrin (CD) inclusion complexes (IC) (EG/CD-IC) were produced via electrospinning technique in order to achieve high thermal stability and slow release of EG. In order to find out the most favorable $\mathrm{CD}$ type for the stabilization of EG, three types of native cyclodextrins $(\alpha-\mathrm{CD}, \beta-\mathrm{CD}$, and $\gamma$ $\mathrm{CD}$ ) were used for the formation of EG/CD-IC. In the case of PVA/EG/ $\alpha$-CD nanofibers, uncomplexed EG was detected indicating that $\alpha$-CD is not a proper host for EG/CD-IC formation. However, for PVA/EG/ $\beta$-CD-IC and PVA/EG/ $\gamma$-CD-IC nanofibers, enhanced durability and high thermal stability for EG were achieved due to the inclusion complexation. The electrospun nanofibers encapsulating CD-IC of active compounds such as eugenol may be quite useful in the food industry due to the extremely large surface area of nanofibers along with specific functionality, enhanced thermal stability, and slow release of the active compounds by $\mathrm{CD}$ inclusion complexation.
\end{abstract}

KEYWORDS: cyclodextrin inclusion complex, electrospinning, eugenol, nanofiber, polyvinyl alcohol (PVA)

\section{INTRODUCTION}

In recent years, the interest in new technologies for active food packaging to prevent food-borne diseases, to provide safety/ quality of nutrition, and to extend shelf life of food has increased significantly. ${ }^{1,2}$ Incorporation of bioactive compounds with antibacterial and/or antioxidant properties, ${ }^{3}$ such as essential oils, ${ }^{4,5}$ bacteriocins, ${ }^{6}$ organic acids, ${ }^{7}$ and enzymes, ${ }^{8}$ has been studied for designing active food packaging materials. However, these bioactive compounds are mostly volatile and temperature sensitive; therefore, their incorporation into polymeric films often faces problems since packaging films are produced by melt extrusion at high temperatures. Very recently, electrospun nanofibrous webs have received some consideration as an active food packaging material due to their very large surface area to volume ratio, nanoscale porosity, and high encapsulation efficiency of active compounds. ${ }^{9}$ Moreover, electrospinning of nanofibers is mostly performed from solution-based systems at room temperature; hence, homogeneous mixing of additives in the fiber matrix can be easily achieved and the evaporation of volatile additives can be prevented. It has been shown that functional nanofibers incorporating bioactive compounds such as antibacterials, antioxidants, fragrances, and essential oils can be effectively obtained by electrospinning method. ${ }^{10-19}$ Yet, compounds having volatile nature may encounter problems related to quick release during the electrospinning process or during the storage of the nanofiber matrix. ${ }^{11-16}$

Eugenol (EG) is a natural fragrance and flavor extracted from plants having antibacterial, ${ }^{20}$ antifungal, $^{21}$ and antioxidant ${ }^{22}$ properties which make this compound more attractive in food industry as a preservative and germicide. However, the use of EG has some limitations due to its low stability since it is easily oxidized or decomposed in the presence of oxygen, light, or heat. ${ }^{23}$ So, the approach of molecular encapsulation by forming cyclodextrin inclusion complexes with EG was considered in order to improve its stability against oxygen, ${ }^{24,25}$ light, ${ }^{24,25}$ and/ or heat. ${ }^{25-28}$
Cyclodextrins (CDs) are nontoxic cyclic oligosaccharides having truncated cone shaped molecular structure (Figure 1a). The most commonly used CD types are named as $\alpha-\mathrm{CD}, \beta-\mathrm{CD}$, and $\gamma$-CD having 6,7 , and 8 glucopyranose units in their cyclic structure, respectively. ${ }^{29-31}$ The depth of the cavity for these three CDs is same which is $\sim 8 \AA$, while the cavity sizes of $\alpha$-CD, $\beta$-CD, and $\gamma-\mathrm{CD}$ are $\sim 6,8$, and $10 \AA$, respectively (Figure $1 \mathrm{a}$ ). ${ }^{29}$ The $\mathrm{CD}$ has the ability to form noncovalent host-guest inclusion complexes with a variety of molecules including drugs, ${ }^{32}$ pesticides, ${ }^{33,34}$ and food additives. ${ }^{35-40}$ Volatile and/or unstable food additives such as essential oils, ${ }^{35,36}$ flavors, ${ }^{37,38}$ and antioxidants ${ }^{39,40}$ can be protected from evaporation, degradation, and oxidation by forming cyclodextrin inclusion complexes (CD-IC). Hence, controlled/slow release, prolonged shelf life, and high temperature stability for these food additives and bioactive compounds could be achieved by CD-IC. ${ }^{35-40}$

The incorporation of CD-IC into electrospun nanofibrous matrix is quite interesting, since these functional nanofibers/ nanowebs have not only high surface area and nanoporous structure, but also the specific properties of CD-IC. ${ }^{11-16}$ Volatile active compounds having high thermal stability, slow release, and prolonged shelf life could be achieved by encapsulation of their CD-IC into electrospun nanofibers/nanowebs. For instance, in our recent studies we have observed that CD-IC of vanillin ${ }^{12}$ and menthol ${ }^{13-15}$ encapsulated into electrospun polymeric nanofiber matrix has shown higher thermal stability and prolonged shelf life when compared those nanofibers without CD-IC.

In this study, electrospun polyvinyl alcohol (PVA) nanofibers encapsulating EG/CD-IC were obtained via electrospinning to improve the thermal stability, and slow release of EG in the fiber matrix. PVA which is a proper polymer type for food packaging ${ }^{41}$

Received: July 3, 2013

Revised: July 29, 2013

Accepted: July 30, 2013

Published: July 30, 2013 
(a)

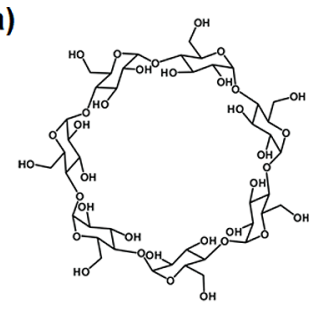

(b)

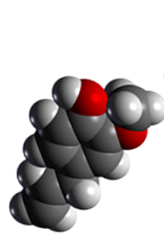

EG

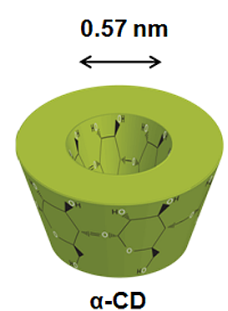

$\alpha-C D$

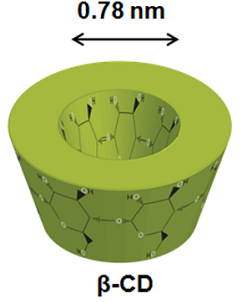

$\beta-C D$

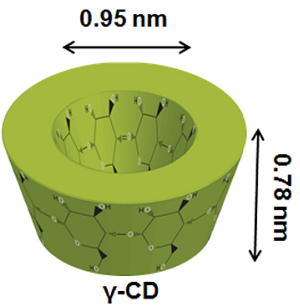

(c)

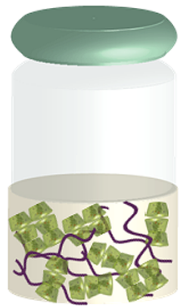

PVA/EG/CD-IC solution

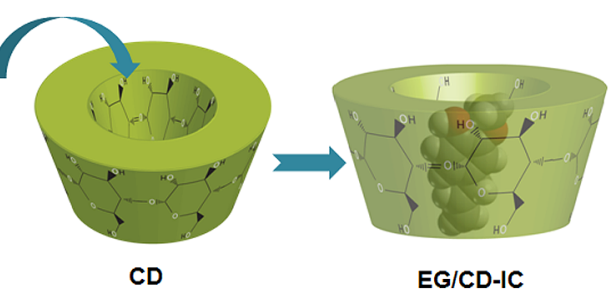

EG/CD-IC

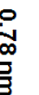

(d)

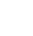

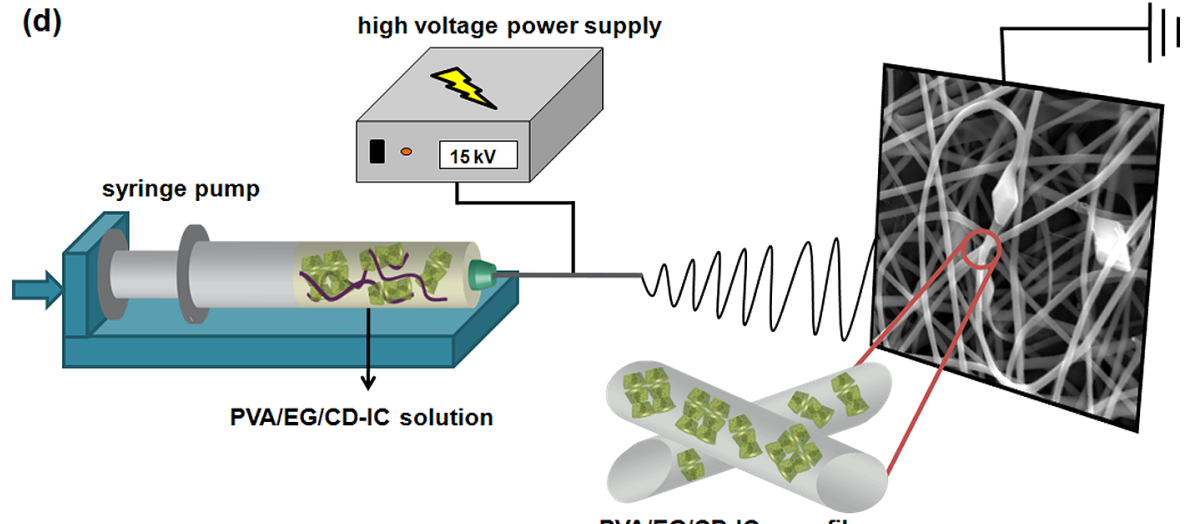

PVA/EG/CD-IC nanofibers

Figure 1. (a) Chemical structure of $\beta$-CD and approximate dimensions of $\alpha$-CD, $\beta$-CD, $\gamma$-CD. Schematic representations of (b) formation of EG/CDIC, (c) PVA/EG/CD-IC solution, and (d) electrospinning of nanofibers from PVA/EG/CD-IC solution.

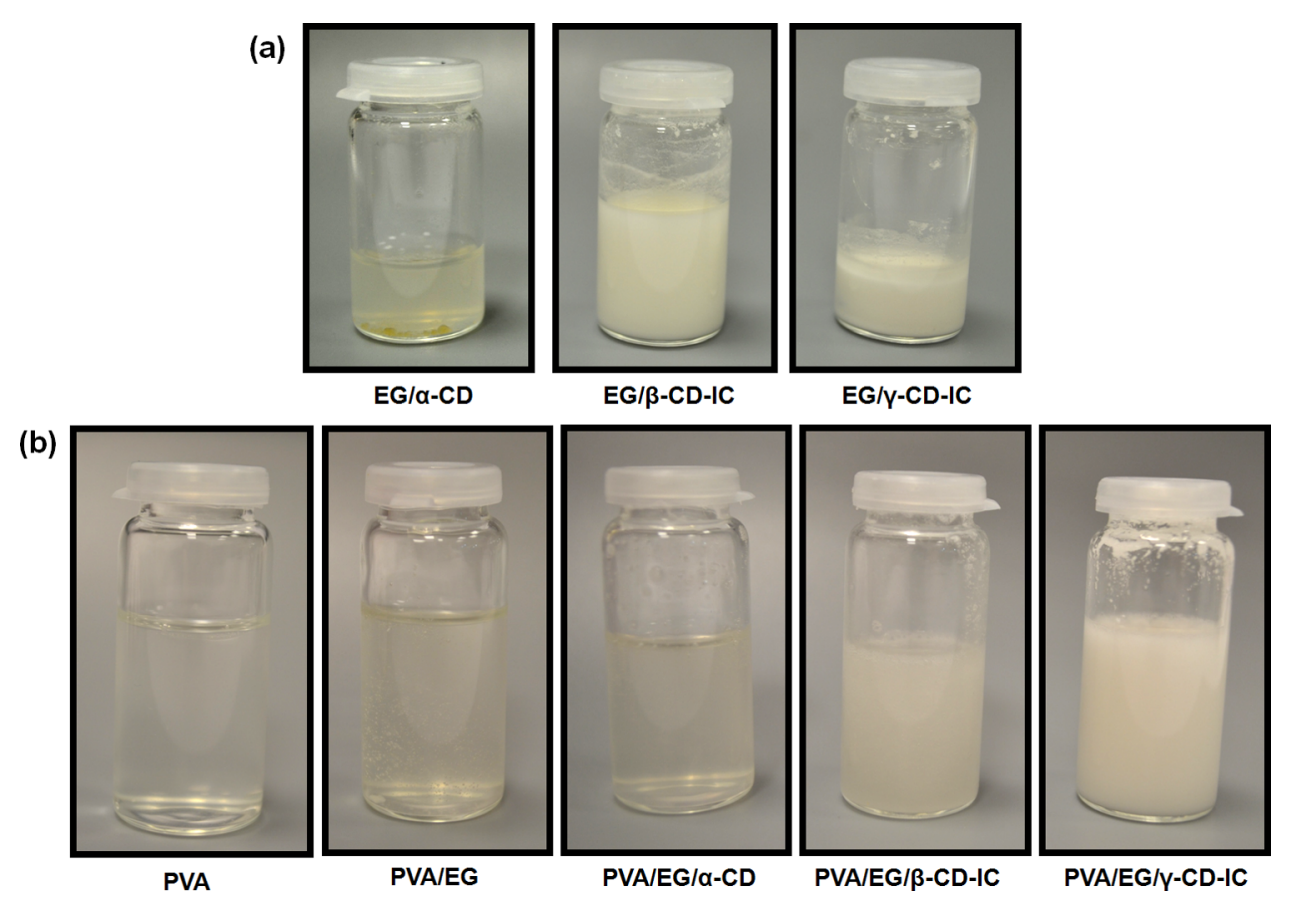

Figure 2. Photographs of the solutions (a) EG/ $\alpha$-CD, EG/ $\beta$-CD-IC, and EG/ $\gamma$-CD-IC, (b) PVA, PVA/EG, PVA/EG/ $\alpha$-CD, PVA/EG/ $\beta$-CD-IC, and PVA/EG/ $\gamma$-CD-IC. 
Table 1. Properties of the Solutions Used for Electrospinning and Morphological Characteristics of the Resulting Electrospun Nanofibers

\begin{tabular}{|c|c|c|c|c|c|c|c|c|}
\hline solution & $\begin{array}{c}\% \mathrm{PVA}^{a} \\
(\mathrm{w} / \mathrm{v})\end{array}$ & $\begin{array}{l}\%, \text { CD type }{ }^{b} \\
(w / w)\end{array}$ & $\begin{array}{l}\% \mathrm{EG}^{b} \\
(\mathrm{w} / \mathrm{w})\end{array}$ & $\begin{array}{l}\text { viscosity } \\
(\mathrm{Pa} \mathrm{s})\end{array}$ & $\begin{array}{l}\text { conductivity } \\
(\mu \mathrm{S} / \mathrm{cm})\end{array}$ & $\begin{array}{l}\text { av fiber diameter } \\
(\mathrm{nm})\end{array}$ & $\begin{array}{l}\text { fiber diameter range } \\
\qquad(\mathrm{nm})\end{array}$ & fiber morphology \\
\hline PVA & 12 & & & 0.66 & 638 & $360 \pm 50$ & $240-480$ & bead-free nanofibers \\
\hline PVA/EG & 12 & & 5 & 1.78 & 618 & $440 \pm 90$ & $210-860$ & bead-free nanofibers \\
\hline $\mathrm{PVA} / \mathrm{EG} / \alpha-\mathrm{CD}$ & 12 & $33 \%, \alpha-\mathrm{CD}$ & 5 & 1.25 & 584 & $520 \pm 120$ & $310-930$ & bead-free nanofibers \\
\hline $\begin{array}{l}\text { PVA/EG/ } \beta \text { - } \\
\text { CD-IC }\end{array}$ & 12 & $39 \%, \beta-\mathrm{CD}$ & 5 & 1.13 & 538 & $610 \pm 110$ & $270-1140$ & $\begin{array}{l}\text { nanofibers with CD-IC } \\
\text { crystals }\end{array}$ \\
\hline $\begin{array}{l}\text { PVA } / E G / \gamma- \\
\text { CD-IC }\end{array}$ & 12 & $44 \%, \gamma-\mathrm{CD}$ & 5 & 1.10 & 578 & $540 \pm 150$ & $310-1170$ & $\begin{array}{l}\text { nanofibers with CD-IC } \\
\text { crystals }\end{array}$ \\
\hline
\end{tabular}

${ }^{a}$ With respect to solvent (water). ${ }^{b}$ With respect to polymer (PVA).

was selected as a polymeric matrix. Here, three types of native $\mathrm{CD}(\alpha-\mathrm{CD}, \beta-\mathrm{CD}$, and $\gamma-\mathrm{CD})$ were used to investigate the effect of $\mathrm{CD}$ type on the IC formation capability with EG and the stability of EG in the CD-IC. We observed enhanced thermal stability and slow release of EG by cyclodextrin inclusion complexation encapsulated in electrospun PVA nanofibers.

\section{MATERIALS AND METHODS}

Materials. Polyvinyl alcohol (PVA, 88\% hydrolyzed, $M_{\mathrm{w}} 125000 \mathrm{~g} /$ mol, SP ${ }^{2}$ Scientific Polymer Products), eugenol (EG, $99 \%$ purity, SigmaAldrich), and deuterated dimethylsulfoxide (DMSO- $d_{6}$, deuteration degree minimum $99.8 \%$ for NMR spectroscopy, Merck) were used in this study. Cyclodextrins $(\alpha-\mathrm{CD}, \beta-\mathrm{CD}$, and $\gamma$-CD) were purchased from Wacker Chemie AG. All materials were used without any purification. The water was from Millipore Milli-Q ultrapure water system.

Preparation of the Solutions. A 1:1 molar ratio of EG with CD $(\alpha-$ $\mathrm{CD}, \beta-\mathrm{CD}$, and $\gamma-\mathrm{CD})$ was used to prepare the inclusion complexes (IC) of EG. First, $\alpha$-CD $\left(0.158 \mathrm{~g}, 1.6 \times 10^{-4} \mathrm{~mol}\right)$ and $\gamma$-CD $(0.21 \mathrm{~g}, 1.6 \times$ $10^{-4} \mathrm{~mol}$ ) were dissolved in 1.1 and $0.9 \mathrm{~mL}$ of water, respectively, at room temperature for $10 \mathrm{~min}$. The amount of water used for these solutions was determined according to the solubility of $\mathrm{CD}$ in water at $25{ }^{\circ} \mathrm{C}$, that is, 14.5 and $23.2 \mathrm{~g} / 100 \mathrm{~mL}$ for $\alpha$-CD and $\gamma$-CD, respectively. ${ }^{29}$ On the other hand, $\beta$-CD $\left(0.185 \mathrm{~g}, 1.6 \times 10^{-4} \mathrm{~mol}\right)$ was dissolved in $2 \mathrm{~mL}$ of water at $75^{\circ} \mathrm{C}$ for $10 \mathrm{~min}$ because of its lower water solubility $(1.85 \mathrm{~g} / 100 \mathrm{~mL})$ compared to other CD types. ${ }^{29}$ Then, EG $\left(24 \mu \mathrm{L}, 0.026 \mathrm{~g}, 1.6 \times 10^{-4} \mathrm{~mol}\right)$ was added to each clear $\mathrm{CD}$ aqueous solution. After mixing the solutions overnight at room temperature, EG/ $\beta$-CD-IC and EG/ $\gamma$-CD-IC solutions became highly turbid due to the formation and suspension of IC aggregates (Figure 2a). On the other hand, EG $/ \alpha$-CD solution was clear, and EG in yellowish color was visually observed (Figure 2a), indicating that the IC could not be formed between EG and $\alpha$-CD under the chosen experimental conditions and the solvent system.

Afterward, PVA solutions were prepared by mixing PVA pellets in water for $2 \mathrm{~h}$ at $75^{\circ} \mathrm{C}$, and the solutions were left at room temperature to cool down. After that, PVA solutions were mixed with EG/ $\alpha$-CD, EG/ $\beta$ $\mathrm{CD}-\mathrm{IC}$, and $\mathrm{EG} / \gamma$-CD-IC solutions individually, and stirred for additional $2 \mathrm{~h}$ at room temperature. $\mathrm{PVA} / \mathrm{EG} / \alpha-\mathrm{CD}$ solution was clear, whereas the solutions of PVA/EG/ $\beta$-CD-IC and PVA/EG/ $\gamma$-CDIC were turbid, indicating aggregates of EG/ $\beta$-CD-IC and EG/ $\gamma$-CD-IC were suspended in aqueous PVA solutions. In addition, we also prepared solutions of PVA and PVA/EG without CD for comparison. The photographs of resulting solutions are given in Figure $2 \mathrm{~b}$. For all solutions, the PVA concentration was kept at $12 \%(\mathrm{w} / \mathrm{v})$ with respect to solvent (water). The EG amount in the solutions was $5 \%(\mathrm{w} / \mathrm{w})$, and the amount of CD was adjusted to $33 \%(\mathrm{w} / \mathrm{w})$ for $\alpha-\mathrm{CD}, 39 \%(\mathrm{w} / \mathrm{w})$ for $\beta$ $\mathrm{CD}$, and $44 \%(\mathrm{w} / \mathrm{w})$ for $\gamma$-CD, with respect to PVA. Table 1 summarizes the compositions of the solutions used for the electrospinning.

$\mathrm{PVA} / \gamma$-CD solution was also prepared by using the same ratio to investigate the possible complexation of PVA with $\gamma$-CD. First, PVA solution was prepared by mixing PVA pellets $[12 \%(\mathrm{w} / \mathrm{v})$ with respect to solvent] in water for $2 \mathrm{~h}$ at $75^{\circ} \mathrm{C}$, and the solution was left at room temperature to cool down. Then, $44 \%$ (w/w) $\gamma$-CD with respect to PVA was added into this PVA solution. After mixing the solution overnight at room temperature, $\mathrm{PVA} / \gamma$-CD solution became clear. Thereafter, PVA/ $\gamma$-CD solution was frozen at $-80{ }^{\circ} \mathrm{C}$ and then lyophilized in a freezedryer (Labconco) in order to obtain solid PVA $/ \gamma$-CD.

Electrospinning. First, each solution was placed in a $3 \mathrm{~mL}$ syringe having metallic needle with $0.8 \mathrm{~mm}$ inner diameter. The syringe was positioned horizontally on the syringe pump (KD Scientific, KDS 101), and the electrode of the high voltage power supply (Spellman, SL Series) was clamped to the metallic needle tip. The electrospinning parameters were adjusted as $15 \mathrm{kV}$ applied voltage, $10 \mathrm{~cm}$ tip-tocollector distance, and $1 \mathrm{~mL} / \mathrm{h}$ flow rate of the solution. Electrospun nanofibers were deposited on the grounded stationary cylindrical collector covered by a piece of aluminum foil. Electrospinning was performed at $23{ }^{\circ} \mathrm{C}$ and $18 \%$ relative humidity in an enclosed Plexiglas box. Finally, the resulting electrospun nanofibers were left in the suction hood at room temperature for $24 \mathrm{~h}$ in order to allow the evaporation of uncomplexed EG if any exists.

Characterization and Measurements. Rheometer (Physica MCR 301, Anton Paar) equipped with a cone/plate accessory (spindle type CP 40-2) was used at a constant shear rate of $1001 / \mathrm{s}$, at $22^{\circ} \mathrm{C}$ to measure the viscosity of the solutions. The conductivity of the solutions was measured with Multiparameter meter InoLab Multi 720 (WTW) at room temperature. Scanning electron microscope (SEM, Quanta 200 FEG, FEI) was used to analyze the morphology and fiber diameter of the electrospun nanofibers. Before SEM imaging, nanofiber samples were coated with $5 \mathrm{~nm} \mathrm{Au} / \mathrm{Pd}$ (PECS-682). The average fiber diameter of each sample was calculated by analyzing around 100 fibers from the SEM images. Fourier transform infrared (FTIR) spectroscopy (BrukerVERTEX 70) was used in order to examine the existence of EG in the electrospun nanowebs. For FTIR analyses, the pellets were prepared by blending a piece of sample with potassium bromide $(\mathrm{KBr})$ and then applying high pressure. The FTIR spectra were recorded with a resolution of $4 \mathrm{~cm}^{-1}$ from 400 to $4000 \mathrm{~cm}^{-1}$ of scanning wavenumber by taking 64 scans for each sample. The proton nuclear magnetic resonance ( ${ }^{1} \mathrm{H}$ NMR, DPX-400, Bruker) spectra were recorded for about $20 \mathrm{~g} / \mathrm{L}$ of the samples dissolved in DMSO- $d_{6}$ at $400 \mathrm{MHz}$ and $25^{\circ} \mathrm{C}$ to confirm the presence of EG in the electrospun nanowebs and to determine the molar stoichiometry of EG/CD. Integration of the resonance peaks $(\delta)$ given in parts per million ( $\mathrm{ppm}$ ) of the samples was calculated by using NMR software. The X-ray diffraction (XRD, PANalyticalX'Pert Powder diffractometer) measurements were carried out by using $\mathrm{Cu} \mathrm{K} \alpha$ radiation in a range $2 \theta=5-30^{\circ}$ to investigate the crystalline structure of the samples. Thermogravimetric analyzer (TGA, Q500, TA Instruments) was used to investigate the thermal properties of the samples. The TGA analysis was performed at a $20^{\circ} \mathrm{C} /$ min heating rate by starting from room temperature to $300{ }^{\circ} \mathrm{C}$ for $\mathrm{EG}$ and to $550{ }^{\circ} \mathrm{C}$ for the nanowebs under nitrogen gas.

The release characteristics of EG from the nanofibers were investigated by headspace gas chromatography-mass spectrometry (GC-MS) analyses that were carried out by using Agilent Technologies 7890A gas chromatography coupled to an Agilent Technologies 5975C inert MSD with a triple-axis detector. The headspace GC-MS experiments were performed with a CTCPAL autosampler by placing $16.6 \mathrm{mg}$ of each nanoweb to $20 \mathrm{~mL}$ of headspace glass vials, and tops of the all vials were firmly closed to avoid the escape of EG. The incubation 

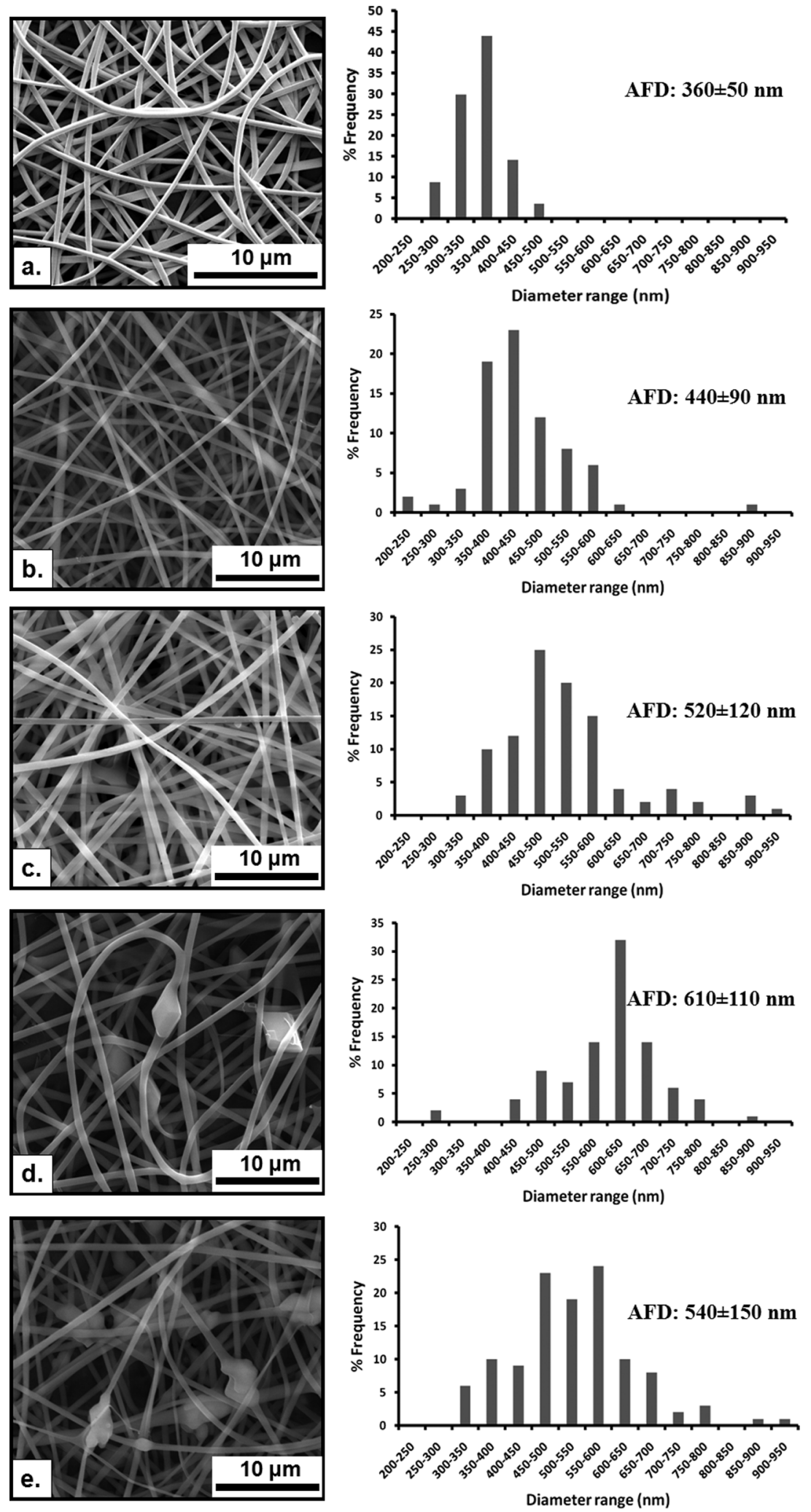

Figure 3. SEM images and fiber diameter distributions with average fiber diameters (AFD) of the electrospun nanofibers obtained from solutions of (a) PVA, (b) PVA/EG, (c) PVA/EG/ $\alpha$-CD, (d) PVA/EG/ $\beta$-CD-IC, and (e) PVA-EG/ $\gamma$-CD-IC.

temperature was determined as 50,75 , and $100^{\circ} \mathrm{C}$, and each sample was shaken sequentially at this temperature for $30 \mathrm{~min}$ at $250 \mathrm{rpm}$ by using an agitator. Headspace injector $(\mathrm{MSH} 02-00 \mathrm{~B}$, volume $=2.5 \mathrm{~mL}$, scale $=$ $60 \mathrm{~mm}$ ) injected $1 \mathrm{~mL}$ of the vapor of the samples to the GC-MS. HP5MS (Hewlett- Packard, Avondale, PA) capillary column with $30 \mathrm{~m} \times$ $0.25 \mathrm{~mm}$ inner diameter and $0.25 \mu \mathrm{m}$ film thickness was used for the separation of compounds. The temperature of the column first was kept at $70{ }^{\circ} \mathrm{C}$ for $2 \mathrm{~min}$ and then raised to $230{ }^{\circ} \mathrm{C}$ at the rate of $20^{\circ} \mathrm{C} / \mathrm{min}$. Finally it was equilibrated at this temperature for $3 \mathrm{~min}$. In these measurements, helium was used as a carrier gas at a flow rate of $1.2 \mathrm{~mL} /$ $\mathrm{min}$. Splitless mode was used in thermal desorption. Ion source and the transfer line temperatures were adjusted to 230 and $280^{\circ} \mathrm{C}$, respectively. 
The GC-MS analyses were performed in the complete scanning mode (SCAN) in the 50-550 mass range, and the characteristic EG peak was determined by comparing its obtained mass spectrum with the EG spectrum in the Flavor 2 library. The peak area of the major peak of EG having 164.1 mass over charge was identified. The headspace GC-MS analyses were done in triplicate, and the standard deviations were calculated accordingly.

\section{RESULTS AND DISCUSSION}

In this study, eugenol/cyclodextrin inclusion complex suspensions $(\mathrm{EG} / \beta$-CD-IC and EG/ $\gamma$-CD-IC) (Figure $2 \mathrm{a}$ ) were mixed with polyvinyl alcohol (PVA) solutions. Then, PVA nanofibers encapsulating EG/ $\beta$-CD-IC and EG/ $\gamma$-CD-IC were successfully obtained from the resulting suspensions (Figure $2 \mathrm{~b}$ ) via electrospinning technique. Schematic representations of the formation of EG/CD-IC, PVA solution incorporating EG/CDIC (PVA/EG/CD-IC), and electrospinning of PVA/EG/CD-IC solution are shown in Figure $1 \mathrm{~b}-\mathrm{d}$. On the other hand, EG did not form inclusion complex with $\alpha$-CD under the applied experimental conditions; therefore, EG with yellowish color was clearly observed in EG/ $\alpha$-CD solution (Figure $2 \mathrm{a}$ ). Yet, EG/ $\alpha$ $\mathrm{CD}$ solution was also mixed with PVA solution, and we obtained PVA nanofibers incorporating $\mathrm{EG} / \alpha-\mathrm{CD}$ mixture for a comparison study. We also produced electrospun nanofibers of PVA, PVA/EG without CD-IC for comparison. Figure 3 shows the representative SEM images and the fiber diameter distributions with average fiber diameters (AFD) of PVA, PVA/EG, PVA/EG/ $\alpha$-CD, PVA/EG/ $\beta$-CD-IC, and PVA/EG/ $\gamma$-CD-IC nanofibers. The electrospun nanofibers of PVA, PVA/ $\mathrm{EG}$, and $\mathrm{PVA} / \mathrm{EG} / \alpha$-CD were uniform. However, the aggregates of EG/ $\beta$-CD-IC and EG/ $\gamma$-CD-IC crystals were present and randomly distributed in PVA fiber matrix in PVA/EG/ $\beta$-CD-IC and PVA $/ E G / \gamma$-CD-IC samples. The variations of fiber diameters were observed among the samples possibly due to differences in viscosity and conductivity of the solutions. Table 1 summarizes the properties of the solutions and the morphological characteristics of the resulting electrospun nanofibers with their AFD and fiber diameter ranges. The viscosity of the PVA/ EG, PVA/EG/ $\alpha$-CD, PVA/EG/ $\beta$-CD-IC, and PVA/EG $/ \gamma$-CDIC solutions was higher than pure PVA solution possibly due to the interactions between the PVA polymer chains and the EG and CD molecules. On the other hand, PVA/EG, PVA/EG/ $\alpha$ $\mathrm{CD}$, PVA/EG/ $\beta$-CD-IC, and PVA/EG/ $\gamma$-CD-IC solutions showed lower conductivity than that of the PVA solution. Both higher viscosity and lower conductivity of the solutions generally result in less stretching of the electrified jet, and therefore, thicker nanofibers are obtained in electrospinning. ${ }^{42-44}$ As anticipated, slightly thicker nanofibers having fiber diameter around $500 \mathrm{~nm}$ were obtained for PVA/EG, PVA/EG/ $\alpha$-CD, PVA/EG/ $\beta$-CD$\mathrm{IC}$, and PVA/EG/ $\gamma$-CD-IC systems when compared to pristine PVA nanofibers having AFD of $360 \pm 50 \mathrm{~nm}$ owing to the higher solution viscosity and lower solution conductivity. Although PVA/EG solution had the highest viscosity, slightly thinner nanofibers were obtained compared to PVA nanofibers containing $\mathrm{CD}$, since the conductivity of the PVA/EG solution was higher than that of PVA/EG/CD solutions. Moreover, the thickest nanofibers were obtained from PVA/EG/ $\beta$-CD-IC system having lowest conductivity, since the polymer solution is being less stretched as a result of the less repulsion of the charges present at the surface. In brief, these findings are parallel with the general observation for electrospinning where viscosity and conductivity of the solutions are the key parameters to affect the fiber diameters of the electrospun nanofibers. ${ }^{42-44}$
The FTIR spectra of $\beta$-CD, EG, and the nanofibers are depicted in Figure 4. Since FTIR spectra of three native CD are

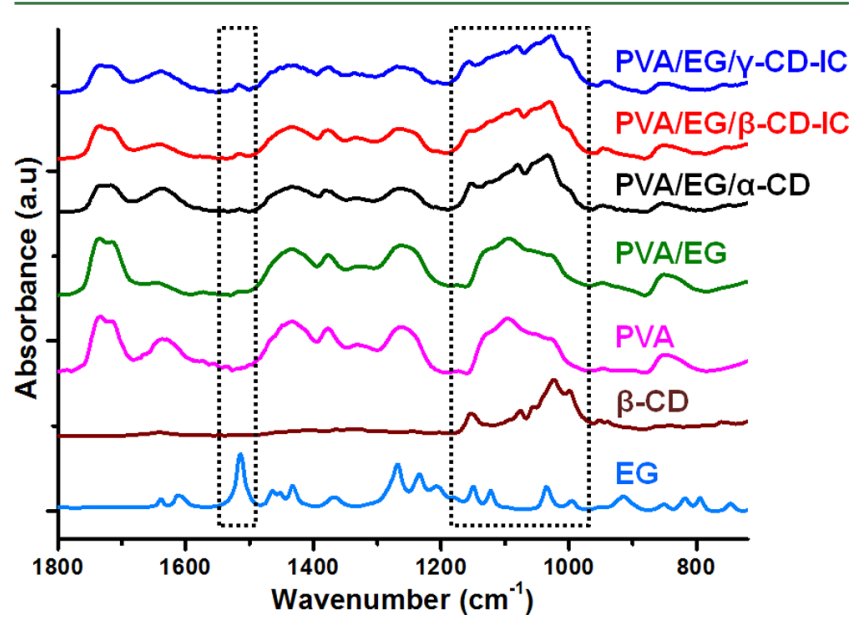

Figure 4. FTIR spectra of EG, $\beta$-CD, and the electrospun nanofibers.

similar, just $\beta$-CD is given as an example. The FTIR spectrum of EG has characteristic peaks in the region of $720-1640 \mathrm{~cm}^{-1}$ assigned to $\mathrm{C}=\mathrm{C}$ region and aromatic ring present in $\mathrm{EG} .{ }^{45,46} \mathrm{In}$ the FTIR spectrum of $\beta-\mathrm{CD}$, the characteristic absorption peaks of $\mathrm{CD}$ were observed at around 1024, 1076, and $1153 \mathrm{~cm}^{-1}$ assigned to the coupled $\mathrm{C}-\mathrm{C} / \mathrm{C}-\mathrm{O}$ stretching vibrations and the asymmetric stretching vibration of the $\mathrm{C}-\mathrm{O}-\mathrm{C}$ glycosidic bridge. $^{38}$ The broad absorption band in the region $1000-1140$ $\mathrm{cm}^{-1}$ in the FTIR spectra of PVA and PVA/EG nanofibers corresponds to the stretching vibration of $\mathrm{C}-\mathrm{O}$ and $\mathrm{C}-\mathrm{O}-\mathrm{C}$ groups in PVA. ${ }^{47}$ This region becomes sharper for PVA/EG/ $\alpha$ $\mathrm{CD}$, PVA/EG/ $\beta$-CD-IC, and PVA/EG/ $\gamma$-CD-IC nanofibers especially due to the presence of distinct characteristic peaks of $\mathrm{CD}$ in the same region. These peaks confirmed the existence of $C D$ in these nanofibers. The overlapping of absorption peaks of PVA, CD, and EG makes the identification of the individual compounds rather complicated in the spectra of the nanofibers. However, the sharpest absorption peak of EG at about $1514 \mathrm{~cm}^{-1}$ which is corresponding to $\mathrm{C}=\mathrm{C}$ stretching of the aromatic moiety was observed for all nanofibers except for pure PVA nanofibers. This confirmed the presence of the EG in the PVA/ EG, PVA/EG $/ \alpha$-CD, PVA/EG/ $\beta$-CD-IC, and PVA/EG $/ \gamma$-CDIC nanofiber samples. Moreover, it was noted that the characteristic peak of EG at $1514 \mathrm{~cm}^{-1}$ was shifted to 1517 $\mathrm{cm}^{-1}$ for PVA/EG/ $\beta$-CD-IC and PVA/EG $/ \gamma$-CD-IC nanofibers, whereas no shift was observed in the case of PVA/EG and PVA/ $\mathrm{EG} / \alpha$-CD nanofibers. The FTIR peak shift for the guest molecules is generally reported for the CD-IC systems due to the interaction between host CD cavity and guest molecules. ${ }^{16,48}$ Here, our FTIR data suggested that the host-guest interactions were present between host $\mathrm{CD}(\beta-\mathrm{CD}$ and $\gamma$-CD) and EG which confirmed the inclusion complexation. ${ }^{49}$

The presence of the EG and $\mathrm{CD}$ in the nanofibers was also confirmed by the ${ }^{1} \mathrm{H}$ NMR studies of the samples (Figure 5). We performed ${ }^{1} \mathrm{H}$ NMR study to calculate the ratio of EG/CD in the nanofibers by integrating the peak ratio of the characteristic resonances corresponding to EG and CD. For this calculation, the evident peaks for EG at about 6.7 and $6.6 \mathrm{ppm},(\mathrm{H}-\mathrm{c}, \mathrm{f}, \mathrm{e})^{50}$ which are not overlapped with the peaks of PVA and CD, were chosen. The intensities of these EG peaks were very weak in the NMR spectrum of PVA/EG nanofibers so the integration of the EG peaks was not possible. This finding indicated that most of 
EG
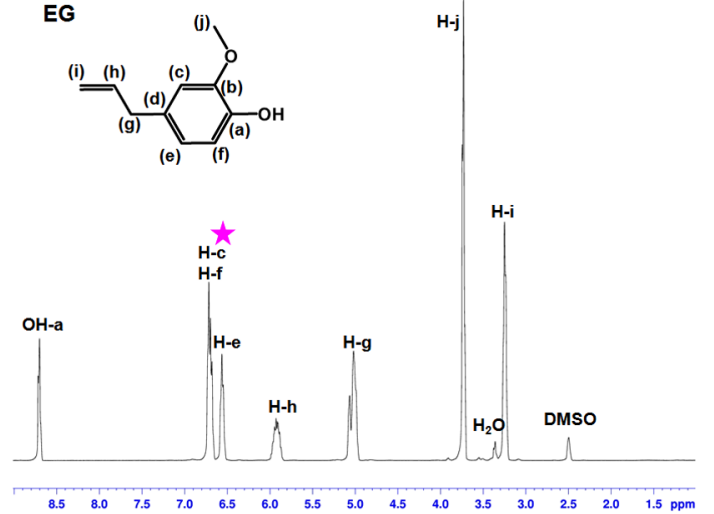

$\begin{array}{lllllllllllllll}8.5 & 8.0 & 7.5 & 7.0 & 6.5 & 6.0 & 5.5 & 5.0 & 4.5 & 4.0 & 3.5 & 3.0 & 2.5 & 2.0 & 1.5 \\ \end{array}$ $\alpha-C D$
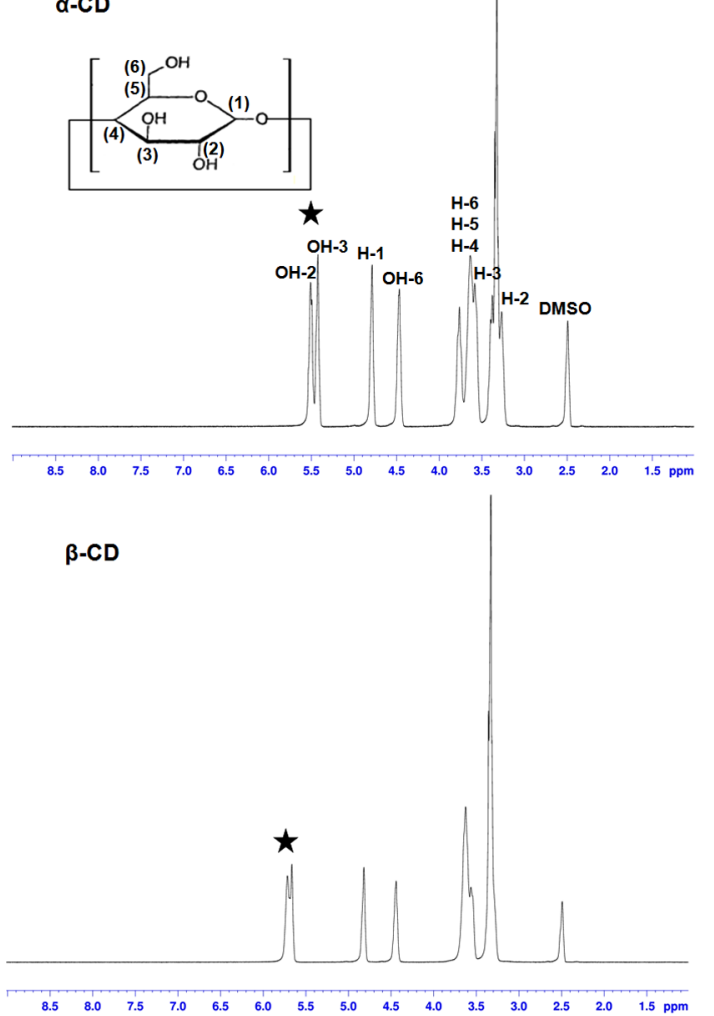

Y-CD
PVA/EG

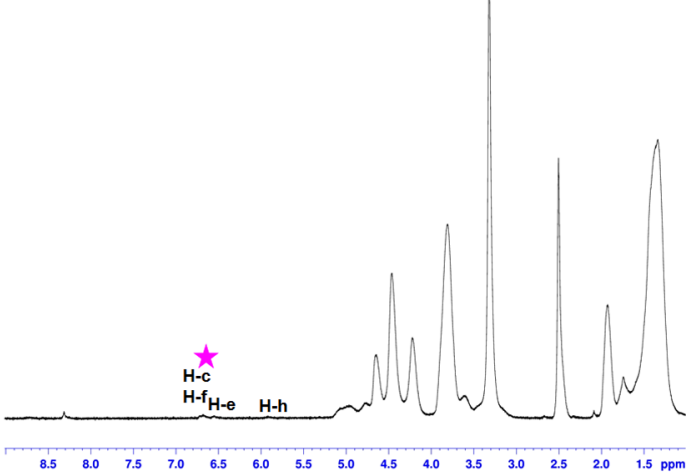

PVA/EG/a-CD

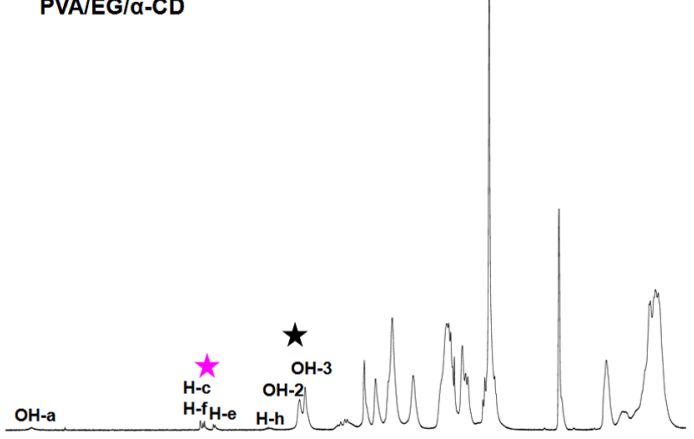

\begin{tabular}{lllllllllllllll}
\hline .5 & 8.0 & 7.5 & 7.0 & 6.5 & 6.0 & 5.5 & 5.0 & 4.5 & 4.0 & 3.5 & 3.0 & 2.5 & 2.0 & $1.5 \mathrm{ppm}$
\end{tabular}

PVA/EG/ $\beta-C D$

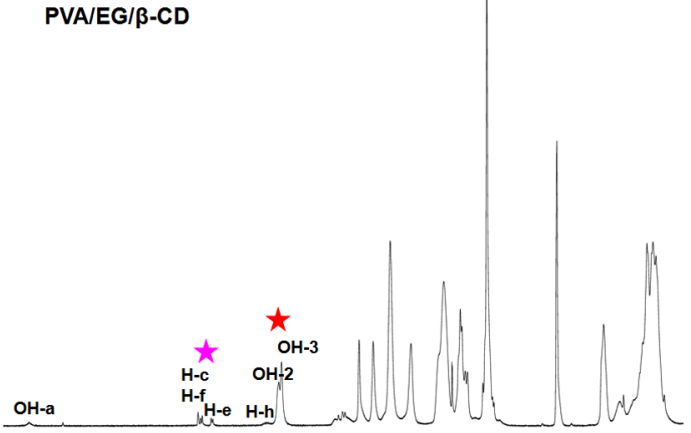

PVA/EG/Y-CD

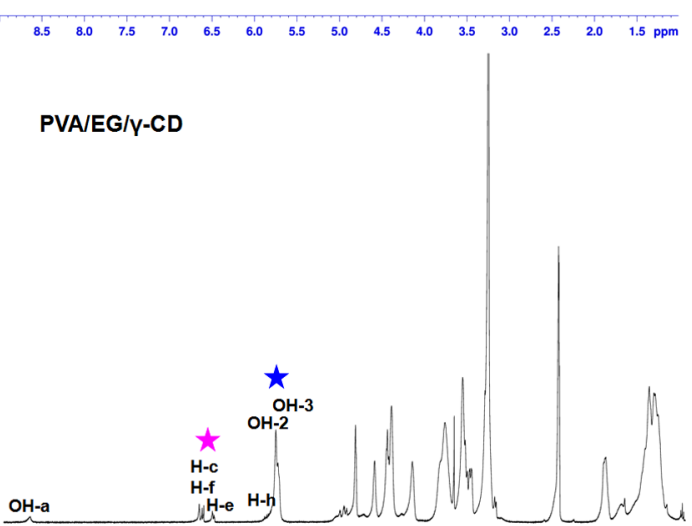
$\mathrm{OH}-\mathrm{a}$

$\begin{array}{llllllllllllllll}8.5 & 8.0 & 7.5 & 7.0 & 6.5 & 6.0 & 5.5 & 5.0 & 4.5 & 4.0 & 3.5 & 3.0 & 2.5 & 2.0 & 1.5 \mathrm{ppm}\end{array}$

Figure 5. ${ }^{1} \mathrm{H}$ NMR spectra of EG, CD, and the electrospun nanofibers. (Protons used for calculation of EG/CD ratio are shown by star sign; pink, EG; black, $\alpha$-CD; red, $\beta$-CD; blue, $\gamma$-CD).

the EG evaporated from this sample during the electrospinning of PVA/EG solution and/or during the storage of the nanofibers in the suction hood for $24 \mathrm{~h}$. This result was also verified by the TGA studies as discussed in the following sections. On the other hand, the peaks of $\mathrm{CD}$ protons $(\mathrm{OH}-2,3)$ at about $5.5 \mathrm{ppm}(\alpha-$ $\mathrm{CD})$ and $5.7 \mathrm{ppm}(\beta-\mathrm{CD})^{38}$ that are not overlapped with the peaks of PVA and EG were taken into account to calculate the ratio of EG and CD molecules in the nanofibers. However, the 

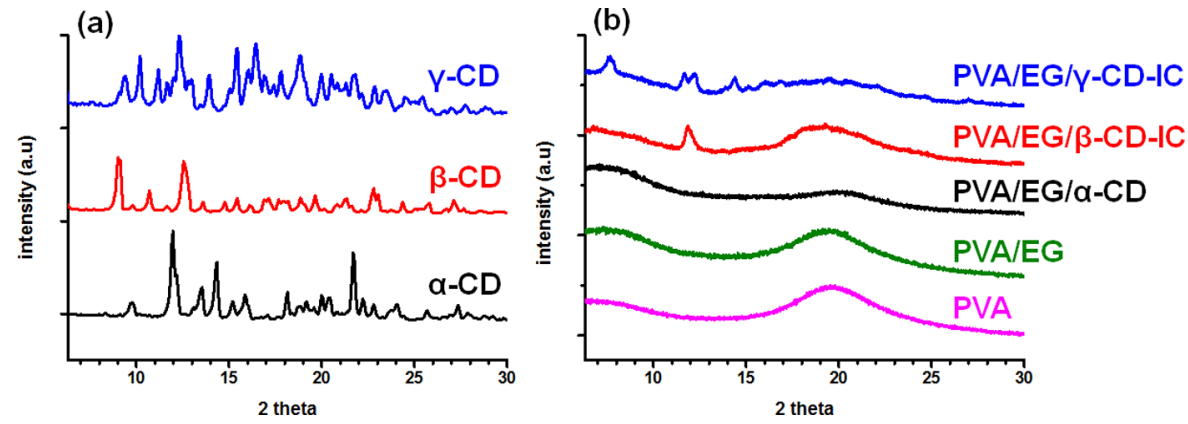

Figure 6. XRD patterns of (a) as-received $C D$ and (b) the electrospun nanofibers.
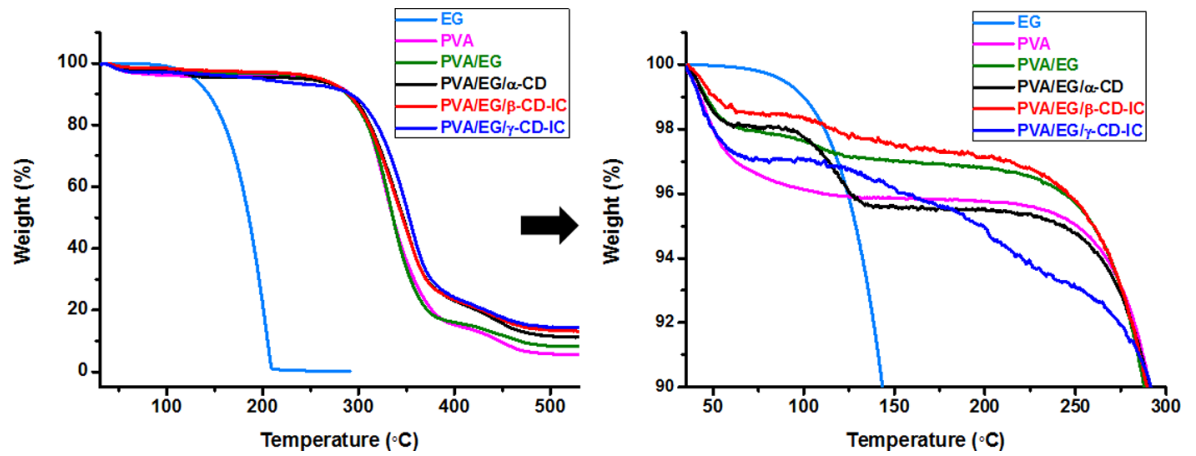

Figure 7. TGA thermograms of EG and the electrospun nanofibers.

peak at about $5.8 \mathrm{ppm}(\mathrm{OH}-2,3)$ in the NMR spectrum of $\gamma$-CD overlaps with the EG peak at $5.9 \mathrm{ppm}(\mathrm{H}-\mathrm{h})$. Therefore, in order to determine the integration of the $\gamma$-CD peaks $(\mathrm{OH}-2,3)$, the integration of EG peak assigned to one proton was subtracted from the integration of this overlapped peak. As a result, it was found that $\mathrm{EG} / \alpha-\mathrm{CD}, \mathrm{EG} / \beta-\mathrm{CD}$, and $\mathrm{EG} / \gamma-\mathrm{CD}$ have stoichiometric ratio as $0.4: 1,0.6: 1$, and $0.8: 1$, respectively, in the PVA nanofibers. The results suggested that the 1:1 initial molar ratio used for the electrospinning process was not conserved especially in the case of PVA/EG/ $\alpha$-CD containing uncomplexed EG. The highest amount of EG observed in PVA/EG/ $\gamma$-CD-IC nanoweb indicated that $\gamma$-CD was the most favorable $\mathrm{CD}$ type for the complexation with a higher amount of EG, possibly due to its proper and larger cavity size compared to $\alpha$-CD and $\beta$-CD.

We have investigated the crystalline structures of the samples by using XRD. The XRD patterns of as-received $\mathrm{CD}$ are given in Figure $6 \mathrm{a}$, and those of nanofibers are depicted in Figure $6 \mathrm{~b}$. The as-received crystalline $\mathrm{CD}$ species $(\alpha-\mathrm{CD}, \beta-\mathrm{CD}$, and $\gamma$-CD) have characteristic diffraction peaks in the range $2 \theta=5-30^{\circ}$ due to their cage-type packing structure as reported in the literature. ${ }^{51,52}$ PVA nanofibers represented a broad diffraction pattern centered at $2 \theta \cong 20^{\circ}$ owing to its semicrystalline nature. A similar broad diffraction pattern was also observed in the XRD pattern of PVA/ EG nanofibers which indicated that EG molecules were distributed in the PVA nanofiber matrix without forming any phase separated crystal aggregates. The XRD pattern of PVA/ EG/ $\alpha$-CD nanofibers had also broad diffraction centered at $2 \theta \cong$ $20^{\circ}$, since $\mathrm{EG} / \alpha-\mathrm{CD}$ was dispersed in the PVA nanofiber matrix without forming any crystalline aggregates. Consequently, the XRD data correlates with SEM images of smooth PVA/EG and PVA/EG/ $\alpha$-CD nanofibers that showed no sign of EG or EG $/ \alpha$ $\mathrm{CD}$ aggregates. For the PVA/EG/ $\beta$-CD-IC sample, the intense diffraction peak at $2 \theta \cong 12^{\circ}$ in the XRD pattern indicated that channel-type packing structure of EG/ $\beta$-CD-IC crystals ${ }^{15,38}$ was present in the PVA nanofiber matrix. In the case of PVA/EG/ $\gamma$ -
CD-IC nanowebs, salient diffraction peaks at $2 \theta \cong 7.5^{\circ}, 11^{\circ}, 12^{\circ}$ along with slightly intense diffraction peaks at $2 \theta \cong 14^{\circ}, 17^{\circ}$, and $22^{\circ}$ were observed elucidating that channel-type crystals of EG/ $\gamma$-CD-IC $38,52,53$ were present in the PVA nanofiber matrix. The complexation of PVA with $\gamma$-CD could be possible as previously reported in Tonelli et al. ${ }^{55}$ However, in our system, the cavity of $\gamma$-CD was already occupied with EG molecules and therefore would not be available to complex with PVA. Nevertheless, we prepared a PVA and $\gamma$-CD aqueous solution and mixed it together, but $\mathrm{PVA} / \gamma$-CD aqueous solution was clear, and no precipitation of CD-IC was observed. The XRD pattern of freeze-dried solid PVA $/ \gamma$-CD sample had a broad diffraction centered at $2 \theta \cong 20^{\circ}$ (data not shown), and the characteristic channel-type packing of $\gamma$-CD was absent. In fact, XRD suggested that $\gamma$-CD was dispersed in the PVA matrix without forming any crystalline aggregates. This result also confirmed that the inclusion complex could not form between PVA and $\gamma$-CD in our experimental conditions. In brief, the channel-type arrangement of the CD molecules in which CD molecules are aligned and stacked on top of each other by forming cylindrical channels is generally used to confirm the formation of inclusion complex. ${ }^{15,38,51-54}$ As a result, XRD studies revealed that EG/ $\beta$-CD-IC and EG/ $\gamma$-CD-IC channel-type crystals were encapsulated in PVA nanofiber matrix. As discussed above, these crystalline EG/ $\beta$-CD-IC and EG/ $\gamma$-CD-IC aggregates were also clearly observed in the SEM images of PVA/EG/ $\beta$-CD-IC and PVA/EG $/ \gamma$-CD-IC nanofibers.

The thermal stability of EG encapsulated in the PVA/EG, PVA/EG/ $\alpha$-CD, PVA/EG/ $\beta$-CD-IC, and PVA/EG/ $\gamma$-CD-IC nanofibers was investigated by the thermogravimetric analyzer (TGA) (Figure 7). The TGA studies of pure EG and PVA nanofibers were also performed for comparison. In the TGA thermogram of pure EG, the weight loss was started at around 70 ${ }^{\circ} \mathrm{C}$, and EG was completely evaporated before $200{ }^{\circ} \mathrm{C}$ which confirms its volatile nature. In the TGA thermogram of PVA 
nanofibers, the initial weight loss until $100{ }^{\circ} \mathrm{C}$ and the major weight loss at above $250^{\circ} \mathrm{C}$ were observed due to dehydration of water and thermal degradation of PVA, respectively. For PVA/ EG nanofibers, three weight loss steps were recorded in the TGA thermograms; the initial weight loss is owing to water loss, the second weight loss around between 70 and $140{ }^{\circ} \mathrm{C}$ is due to the evaporation of EG, and the main weight loss started at around $250{ }^{\circ} \mathrm{C}$ corresponds to the main degradation of PVA. Although $5 \%$ (w/w, with respect to PVA) of EG was used for the preparation of all nanofiber samples, from the TGA data only $0.8 \%$ weight loss of EG (w/w, with respect to PVA) was observed in PVA/EG nanofibers. Therefore, around $85 \%$ of EG has already been lost during the electrospinning of PVA/EG solution and/or during the storage of the PVA/EG nanofibers in a suction hood for $24 \mathrm{~h}$. As also mentioned in the previous section, the integration of NMR peaks of EG in this sample even could not be calculated because of its low amount. The TGA thermogram of PVA/EG/ $\alpha$-CD nanofibers has shown three-step weight losses at comparable temperature range as PVA/EG nanofibers. The evaporation temperature of the EG in PVA/EG and PVA/EG/ $\alpha$ $\mathrm{CD}$ nanofibers was very similar to evaporation temperature of pure EG. It is known that the thermal degradation/evaporation of the volatile guest molecules shifts to higher temperatures in CD-IC owing to the interactions with the CD cavity. ${ }^{38,56,57}$ Our result suggested that PVA nanofiber matrix could not enhance the thermal stability of EG without CD-IC, and so could not effectively preserve the EG at high temperature. Similar to PVA/ $\mathrm{EG}, \mathrm{EG}$ was in uncomplexed state in PVA/EG/ $\alpha$-CD nanofibers; therefore, the thermal stability of EG could not be improved. However, TGA thermogram of PVA/EG/ $\alpha$-CD nanofibers showed $2.45 \%$ weight loss of EG which corresponds to $33 \%$ (w/ w) lost of EG from the initial amount used for this sample. Although $\alpha$-CD and EG were not in the complex state, the remaining amount of EG in PVA/EG/ $\alpha$-CD nanofibers was much higher than the PVA/EG nanofibers. The presence of $\alpha$ $\mathrm{CD}$ somehow preserves a higher amount of EG in the nanofiber sample, and this may be because of some interaction, possibly hydrogen bonding between $\mathrm{OH}$ groups of $\alpha$-CD and EG molecules.

On the other hand, higher thermal stability of EG was observed for PVA nanofibers incorporating EG/CD-IC compared to PVA/EG and PVA/EG/ $\alpha$-CD nanofibers. For PVA/EG/ $\beta$-CD-IC nanofibers, the weight loss of EG started at around $100{ }^{\circ} \mathrm{C}$. In the case of PVA/EG/ $\gamma$-CD-IC nanofibers, the weight loss of $\mathrm{EG}$ was observed up to $120^{\circ} \mathrm{C}$, elucidating that the thermal stability of EG was improved more significantly for this sample compared to PVA/EG/ $\beta$-CD-IC. The higher thermal stability of EG in PVA/EG/ $\gamma$-CD-IC nanofibers suggested that the strength of interaction between EG and the $\gamma$-CD cavity was stronger when compared to $\beta-\mathrm{CD}$, as also confirmed by headspace GC-MS analyses discussed in the following section. Moreover, in PVA/EG/CD-IC samples, the evaporation of EG possibly continued above $250{ }^{\circ} \mathrm{C}$ where main degradation of $\mathrm{CD}$ and PVA started, and therefore, we could not use TGA thermograms for determining the actual weight content of EG in the PVA/EG/CD-IC (PVA/EG/ $\beta$-CD-IC and PVA/EG $/ \gamma$ CD-IC) nanofibers. So, as previously discussed, ${ }^{1} \mathrm{H}$ NMR analyses were performed for calculation of actual EG content in these samples. However, as it is seen in Figure 7, the \% EG weight loss was higher for PVA/EG/ $\gamma$-CD-IC compared to PVA/EG/ $\beta$ $\mathrm{CD}$-IC signifying that the amount of EG presented in this sample was higher, as also confirmed by ${ }^{1} \mathrm{H}$ NMR analysis.
Headspace GC-MS technique was used to investigate the thermal stability and release characteristics of $\mathrm{EG}$ in the nanofibers. Therefore, the release ratio of EG at 50,75, and $100{ }^{\circ} \mathrm{C}$ from each sample was determined from the corrected area of the major peak of EG in each headspace GC-MS chromatogram, and the results are summarized in Figure 8. The

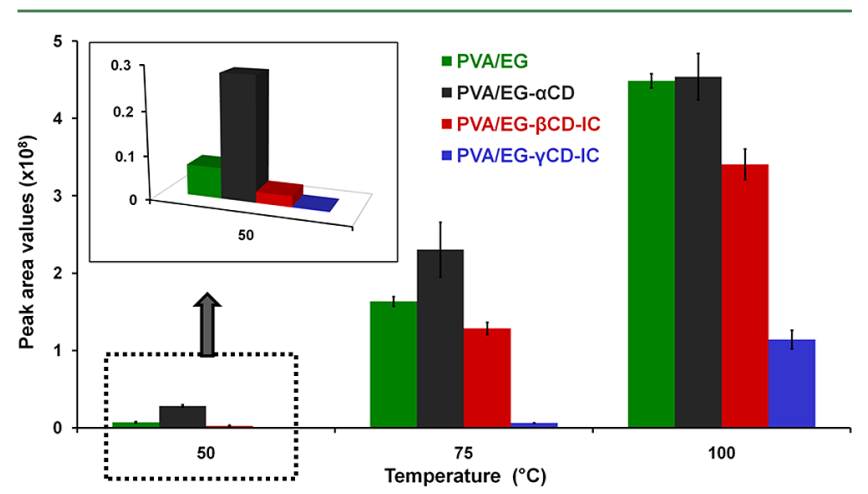

Figure 8. Peak areas of EG in headspace GC-MS chromatogram of electrospun nanofibers agitated at 50,75 , and $100{ }^{\circ} \mathrm{C}$ for $30 \mathrm{~min}$.

headspace GC-MS analyses clearly showed that the amount of released $\mathrm{EG}$ is higher when the temperature increases from 50 to $100{ }^{\circ} \mathrm{C}$. According to ${ }^{1} \mathrm{H}$ NMR data, the relative amount of EG was in the order PVA/EG/ $\gamma$-CD-IC > PVA $/ E G / \beta$-CD-IC > $\mathrm{PVA} / \mathrm{EG} / \alpha$-CD $>$ PVA/EG. Both PVA/EG/ $\alpha$-CD and PVA/ EG contain uncomplexed EG, but the relative amount of released EG was higher for PVA/EG/ $\alpha$-CD compared to PVA/EG since the actual EG content presented in the PVA/EG/ $\alpha-\mathrm{CD}$ nanofibers was more than that of PVA/EG nanofibers as confirmed by ${ }^{1} \mathrm{H}$ NMR and TGA data. Although PVA/EG/ $\beta$ CD-IC nanofibers contain a much higher amount of EG compared to PVA/EG, it was observed that the release of EG from PVA/EG/ $\beta$-CD-IC sample was comparable to PVA/EG sample indicating that presence of $\mathrm{EG} / \beta$-CD-IC in PVA nanofibers enhanced the slow release of EG at higher temperature. In the case of PVA/EG/ $\gamma$-CD-IC nanofibers, the least amount of EG was released although this sample has the highest amount of EG compared to other samples. The slow release of EG at each temperature from PVA/EG/ $\gamma$-CD-IC nanofibers clearly showed that the enhanced durability and higher thermal stability was achieved for EG due to inclusion complexation with $\gamma$-CD. This elucidated that $\gamma$-CD is the most effective native $\mathrm{CD}$ type for the high temperature stabilization of EG in our systems. This finding was also correlated with the results of the TGA study. In short, the higher temperature stable inclusion complex was formed between EG and $\gamma$-CD. This is possibly due to bigger cavity size of $\gamma$-CD which results in a better fit and size match between the EG molecule and the $\gamma$-CD cavity. To sum up, both TGA and headspace GC-MS studies revealed that the CD-IC provided higher thermal stability and slow release of EG in the nanofibers; in addition, the choice of CD type is also important for better thermal stability of EG.

In conclusion, in order to obtain functional nanofibers/ nanowebs containing EG with enhanced thermal stability and durability, PVA nanofibers encapsulating EG/CD-IC were successfully produced via electrospinning technique. Here, three types of $\mathrm{CD}, \alpha-\mathrm{CD}, \beta-\mathrm{CD}$, and $\gamma$-CD, were used for the formation of EG/CD-IC, and our results showed that the size/ shape fit between the host $\mathrm{CD}$ and guest EG molecule is an important factor for forming inclusion complexation. EG could 
not be complexed with a small cavity size of $\alpha$-CD. Hence, PVA nanofibers encapsulating EG only and EG/ $\alpha$-CD could not preserve the EG due to its highly volatile nature. On the other hand, thermal evaporation of EG in PVA/EG/ $\beta$-CD-IC and PVA/EG/ $\gamma$-CD-IC nanofibers shifted to higher temperature when compared to pure EG; moreover, much slower release of EG at elevated temperature $\left(50,75\right.$, and $\left.100{ }^{\circ} \mathrm{C}\right)$ was achieved for PVA/EG/ $\beta$-CD-IC and PVA/EG/ $\gamma$-CD-IC nanofibers due to inclusion complexation. In addition, higher thermal stability and the slower release of EG was observed for PVA/EG/ $\gamma$-CDIC indicating that $\gamma$-CD was the most suitable host for EG when compared to $\alpha$-CD and $\beta$-CD. EG is a widely used bioactive compound as a fragrance and flavoring in the food industry due to its antibacterial, antioxidant, and antifungal properties. So, these functional electrospun PVA nanofibers encapsulating EG/ CD-IC having very high surface area and a nanoporous structure as well as the properties of EG/CD-IC may have practical application in food industry and active food packaging, etc.

\section{AUTHOR INFORMATION}

\section{Corresponding Author}

*E-mail: tamer@unam.bilkent.edu.tr. Phone: (+90) 3122903571. Fax: (+90)3122664365.

\section{Notes}

The authors declare no competing financial interest.

\section{ACKNOWLEDGMENTS}

State Planning Organization (DPT) of Turkey is acknowledged for the support of UNAM-Institute of Materials Science and Nanotechnology. T.U. acknowledges The Scientific and Technological Research Council of Turkey (TUBITAK) (Project 111M459) and EU FP7-PEOPLE-2009-RG Marie Curie-IRG (NANOWEB, PIRG06-GA-2009-256428) and The Turkish Academy of Sciences-Outstanding Young Scientists Award Program (TUBA-GEBIP) for funding the research. F.K. acknowledges TUBITAK-BIDEB, and Y.E. acknowledges TUBITAK (Project \# 110M612) for the national Ph.D. student scholarship.

\section{REFERENCES}

(1) Caleb, O. J.; Mahajan, P. V.; Al-Said, F. A.-J.; Opara, U. L. Modified atmosphere packaging technology of fresh and fresh-cut produce and the microbial consequences-A review. Food Bioprocess Technol. 2012, $1-27$.

(2) Majeed, K.; Jawaid, M.; Hassan, A.; Abu Bakar, A.; Abdul Khalil, H.; Salema, A.; Inuwa, I. Potential materials for food packaging from nanoclay/natural fibres filled hybrid composites. Mater. Des. 2013, 66, 391-410.

(3) Appendini, P.; Hotchkiss, J. H. Review of antimicrobial food packaging. Innovative Food Sci. Emerging Technol. 2002, 3, 113-126.

(4) Del Nobile, M.; Conte, A.; Incoronato, A.; Panza, O. Antimicrobial efficacy and release kinetics of thymol from zein films. J. Food Eng. 2008, $89,57-63$.

(5) Rodriguez, A.; Nerin, C.; Batlle, R. New cinnamon-based active paper packaging against Rhizopusstolonifer food spoilage. J. Agric. Food Chem. 2008, 56, 6364-6369.

(6) de Oliveira, T. M.; de Fátima Ferreira Soares, N.; Pereira, R. M.; de Freitas Fraga, K. Development and evaluation of antimicrobial natamycin-incorporated film in gorgonzola cheese conservation. Packag. Technol. Sci. 2007, 20, 147-153.

(7) Schirmer, B. C.; Heiberg, R.; Eie, T.; Møretrø, T.; Maugesten, T.; Carlehøg, M.; Langsrud, S. A novel packaging method with a dissolving $\mathrm{CO}_{2}$ headspace combined with organic acids prolongs the shelf life of fresh salmon. Int. J. Food Microbiol. 2009, 133, 154-160.
(8) Appendini, P.; Hotchkiss, J. H. Immobilization of lysozyme on food contact polymers as potential antimicrobial films. Packag. Technol. Sci. 1998, 10, 271-279.

(9) Kriegel, C.; Arrechi, A.; Kit, K.; McClements, D.; Weiss, J. Fabrication, functionalization, and application of electrospun biopolymer nanofibers. Crit. Rev. Food Sci. 2008, 48, 775-797.

(10) Sun, L.-M.; Zhang, C.-L.; Li, P. Characterization, antimicrobial activity, and mechanism of a high-performance (-)-epigallocatechin-3gallate (EGCG)-CuII/polyvinyl alcohol (PVA) nanofibrous membrane. J. Agric. Food Chem. 2011, 59, 5087-5092.

(11) Vega-Lugo, A. C.; Lim, L. T. Controlled release of allyl isothiocyanate using soy protein and poly (lactic acid) electrospun fibers. Food Res. Int. 2009, 42, 933-940.

(12) Kayaci, F.; Uyar, T. Encapsulation of vanillin/cyclodextrin inclusion complex in electrospun polyvinyl alcohol (PVA) nanowebs: Prolonged shelf-life and high temperature stability of vanillin. Food Chem. 2012, 59, 11772-11778.

(13) Uyar, T.; Nur, Y.; Hacaloglu, J.; Besenbacher, F. Electrospinning of functional poly (methyl methacrylate) nanofibers containing cyclodextrin-menthol inclusion complexes. Nanotechnology 2009, 20, 125703.

(14) Uyar, T.; Hacaloglu, J.; Besenbacher, F. Electrospun polystyrene fibers containing high temperature stable volatile fragrance/flavor facilitated by cyclodextrin inclusion complexes. React. Funct. Polym. 2009, 69, 145-150.

(15) Uyar, T.; Hacaloglu, J.; Besenbacher, F. Electrospun polyethylene oxide (PEO) nanofibers containing cyclodextrin inclusion complex. J. Nanosci. Nanotechnol. 2011, 11, 3949-3958.

(16) Kayaci, F.; Umu, O. C.; Tekinay, T.; Uyar, T. Antibacterial electrospun poly (lactic acid) (PLA) nanofibrous webs incorporating triclosan/cyclodextrin inclusion complexes. J. Agric. Food Chem. 2013, 61, 3901-3908.

(17) Li, Y.; Lim, L. T.; Kakuda, Y. Electrospun zein fibers as carriers to stabilize (-)-epigallocatechin gallate. J. Food Sci. 2009, 74, C233-C240.

(18) Fernandez, A.; Torres-Giner, S.; Lagaron, J. M. Novel route to stabilization of bioactive antioxidants by encapsulation in electrospun fibers of zein prolamine. Food Hydrocolloids 2009, 23, 1427-1432.

(19) Neo, Y. P.; Ray, S.; Jin, J.; Gizdavic-Nikolaidis, M.; Nieuwoudt, M. K.; Liu, D.; Quek, S. Y. Encapsulation of food grade antioxidant in natural biopolymer by electrospinning technique: a physicochemical study based on zein-gallic acid system. Food Chem. 2012, 136, 10131021.

(20) Laekeman, G.; Van Hoof, L.; Haemers, A.; Berghe, D.; Herman, A.; Vlietinck, A. Eugenol a valuable compound for in vitro experimental research and worthwhile for further in vivo investigation. Phytother. Res. 1990, 4, 90-96

(21) Cheng, S. S.; Liu, J. Y.; Chang, E. H.; Chang, S. T. Antifungal activity of cinnamaldehyde and eugenol congeners against wood-rot fungi. Bioresour. Technol. 2008, 99, 5145-5149.

(22) Atsumi, T.; Fujisawa, S.; Tonosaki, K. A comparative study of the antioxidant/prooxidant activities of eugenol and isoeugenol with various concentrations and oxidation conditions. Toxicol. In Vitro 2005, 19, $1025-1033$.

(23) Shimoda, K.; Kondo, Y.; Nishida, T.; Hamada, H.; Nakajima, N. Biotransformation of thymol, carvacrol, and eugenol by cultured cells of Eucalyptus perriniana. Phytochemistry 2006, 67, 2256-2261.

(24) Chun, J.-Y.; You, S.-K.; Lee, M.-Y.; Choi, M.-J.; Min, S.-G. Characterization of $\beta$-cyclodextrin self-aggregates for eugenol encapsulation. J. Food Eng. 2012, 8, 17.

(25) Choi, M. J.; Soottitantawat, A.; Nuchuchua, O.; Min, S. G.; Ruktanonchai, U. Physical and light oxidative properties of eugenol encapsulated by molecular inclusion and emulsion-diffusion method. Food Res. Int. 2009, 42, 148-156.

(26) Zhan, H.; Jiang, Z. T.; Wang, Y.; Li, R.; Dong, T. S. Molecular microcapsules and inclusion interactions of eugenol with $\beta$-cyclodextrin and its derivatives. Eur. Food Res. Technol. 2008, 227, 1507-1513.

(27) Wang, T.; Li, B.; Si, H.; Lin, L.; Chen, L. Release characteristics and antibacterial activity of solid state eugenol/ $\beta$-cyclodextrin inclusion complex. J. Inclusion Phenom. Macrocyclic Chem. 2011, 71, 207-213. 
(28) Gomes, C.; Moreira, R. G.; Castell-Perez, E. Microencapsulated antimicrobial compounds as a means to enhance electron beam irradiation treatment for inactivation of pathogens on fresh spinach leaves. J. Food Sci. 2011, 76, E479-E488.

(29) Szejtli, J. Introduction and general overview of cyclodextrin chemistry. Chem. Rev. 1998, 98, 1743-1754.

(30) Hedges, A. R. Industrial applications of cyclodextrins. Chem. Rev. 1998, 98, 2035-2044.

(31) Del Valle, E. M. Cyclodextrins and their uses: A review. Process Biochem. 2004, 39, 1033-1046.

(32) Vyas, A.; Saraf, S.; Saraf, S. Cyclodextrin based novel drug delivery systems. J. Inclusion Phenom. Macrocyclic Chem. 2008, 62, 23-42.

(33) Zhu, X.-L.; Wang, H.-B.; Chen, Q.; Yang, W.-C.; Yang, G.-F. Preparation and characterization of inclusion complex of iprodione and $\beta$-cyclodextrin to improve fungicidal activity. J. Agric. Food Chem. 2007, $55,3535-3539$.

(34) Yang, G.-F.; Wang, H.-B.; Yang, W.-C.; Gao, D.; Zhan, C.-G. Bioactive permethrin $/ \beta$-cyclodextrin inclusion complex. J. Phys. Chem. B 2006, 110, 7044-7048.

(35) Marques, H. M. C. A review on cyclodextrin encapsulation of essential oils and volatiles. Flavour Fragrance J. 2010, 25, 313-326.

(36) Samperio, C.; Boyer, R.; Eigel, W. N., III; Holland, K. W.; McKinney, J. S.; O'Keefe, S. F.; Smith, R.; Marcy, J. E. Enhancement of plant essential oils' aqueous solubility and stability using alpha and beta cyclodextrin. J. Agric. Food Chem. 2010, 58, 12950-12956.

(37) Kant, A.; Linforth, R. S. T.; Hort, J.; Taylor, A. J. Effect of $\beta$ cyclodextrin on aroma release and flavor perception. J. Agric. Food Chem. 2004, 52, 2028-2035.

(38) Kayaci, F.; Uyar, T. Solid inclusion complexes of vanillin with cyclodextrins: Their formation, characterization, and high-temperature stability. J. Agric. Food Chem. 2011, 59, 11772-11778.

(39) Huang, D.; Ou, B.; Hampsch-Woodill, M.; Flanagan, J. A.; Deemer, E. K. Development and validation of oxygen radical absorbance capacity assay for lipophilic antioxidants using randomly methylated $\beta$ cyclodextrin as the solubility enhancer. J. Agric. Food Chem. 2002, 50, $1815-1821$

(40) Koontz, J. L.; Marcy, J. E.; O'Keefe, S. F.; Duncan, S. E. Cyclodextrin inclusion complex formation and solid-state characterization of the natural antioxidants $\alpha$-tocopherol and quercetin. J. Agric. Food Chem. 2009, 57, 1162-1171.

(41) DeMerlis, C.; Schoneker, D. Review of the oral toxicity of polyvinyl alcohol (PVA). Food Chem. Toxicol. 2003, 41, 319-326.

(42) Wendorff, J. H.; Agarwal, S.; Greiner, A. Electrospinning: Materials, Processing, and Applications; John Wiley \& Sons: Weinheim, Germany, 2012.

(43) Ramakrishna, S. An Introduction to Electrospinning and Nanofibers; World Scientific Publishing: London, 2005.

(44) Uyar, T.; Besenbacher, F. Electrospinning of uniform polystyrene fibers: The effect of solvent conductivity. Polymer 2008, 49, 5336-5343.

(45) Nuchuchua, O.; Saesoo, S.; Sramala, I.; Puttipipatkhachorn, S.; Soottitantawat, A.; Ruktanonchai, U. Physicochemical investigation and molecular modeling of cyclodextrin complexation mechanism with eugenol. Food Res. Int. 2009, 42, 1178-1185.

(46) Sajomsang, W.; Nuchuchua, O.; Gonil, P.; Saesoo, S.; Sramala, I.; Soottitantawat, A.; Puttipipatkhachorn, S.; Ruktanonchai, U. R. Watersoluble $\beta$-cyclodextrin grafted with chitosan and its inclusion complex as a mucoadhesive eugenol carrier. Carbohydr. Polym. 2012, 89, 623-631.

(47) Chahal, R. P.; Mahendia, S.; Tomar, A.; Kumar, S. $\gamma$-Irradiated PVA/Ag nanocomposite films: materials for optical applications. J. Alloys Compd. 2012, 538, 212-219.

(48) Celebioglu, A.; Uyar, T. Electrospinning of polymer-free nanofibers from cyclodextrin inclusion complexes. Langmuir 2011, 27, 6218-6226.

(49) Yang, Y.; Song, L. X. Study on the inclusion compounds of eugenol with $\alpha$-, $\beta$-, $\gamma$-and heptakis (2, 6-di-O-methyl)- $\beta$-cyclodextrins. J. Inclusion Phenom. Macrocyclic Chem. 2005, 53, 27-33.

(50) Locci, E.; Lai, S.; Piras, A.; Marongiu, B.; Lai, A. ${ }^{13}$ C-CPMAS and ${ }^{1} \mathrm{H}$-NMR study of the inclusion complexes of $\beta$-cyclodextrin with carvacrol, thymol, and eg prepared in supercritical carbon dioxide. Chem. Biodiversity 2004, 1, 1354-1366.

(51) Saenger, W.; Jacob, J.; Gessler, K.; Steiner, T.; Hoffmann, D.; Sanbe, H.; Koizumi, K.; Smith, S. M.; Takaha, T. Structures of the common cyclodextrins and their larger analogues-Beyond the doughnut. Chem. Rev. 1998, 98, 1787-1802.

(52) Rusa, C. C.; Bullions, T. A.; Fox, J.; Porbeni, F. E.; Wang, X.; Tonelli, A. E. Inclusion compound formation with a new columnar cyclodextrin host. Langmuir 2002, 18, 10016-10023.

(53) Uyar, T.; Hunt, M. A.; Gracz, H. S.; Tonelli, A. E. Crystalline cyclodextrin inclusion compounds formed with aromatic guests: guestdependent stoichiometries and hydration-sensitive crystal structures. Cryst. Growth Des. 2006, 6 (5), 1113-1119.

(54) Harata, K. Structural aspects of stereodifferentiation in the solid state. Chem. Rev. 1998, 98, 1803-1827.

(55) Hernández, R.; Rusa, M.; Rusa, C. C.; López, D.; Mijangos, C.; Tonelli, A. E. Controlling PVA hydrogels with $\gamma$-cyclodextrin. Macromolecules 2004, 37, 9620-9625.

(56) Tsai, Y.; Tsai, H. H.; Wu, C. P.; Tsai, F. J. Preparation, characterisation and activity of the inclusion complex of paeonol with $\beta$ cyclodextrin. Food Chem. 2010, 120, 837-841.

(57) Marcolino, V. A.; Zanin, G. M.; Durrant, L. R.; Benassi, M. D. T.; Matioli, G. Interaction of curcumin and bixin with $\beta$-cyclodextrin: complexation methods, stability, and applications in food. J. Agric. Food Chem. 2011, 59, 3348-3357. 